\title{
Nutritional care in patient care in palliative care: systematic review
}

\begin{abstract}
Objective: To characterize, through a systematic review of the literature, the nutritional care of patients in palliative care/termination of life, in front of the multidisciplinary team.

Data Source: Medline was used as a database for searching the information.

Data Synthesis: The search for studies resulted in 348 searches. After the methodological sieve, two studies were selected to compose this review. The studies pointed out the importance of nutritional care vis-à-vis the view of other health professionals and palliative care patients who received it at an early stage.
\end{abstract}

Conclusion: Despite the scarce number of scientific evidence on the subject, we conclude that nutritional care is important and widespread among other palliative professionals. New research could be carried out with the purpose of directing the Nutritionist professionals in daily clinical practice.

Keywords: palliative care, nutrition, hospice care, assistance
Volume 2 Issue 2 - 2018

\section{Nathalia Sernizon Guimarães, Valéria Alvarenga Medeiros, Júlio César Batista Santana \\ Faculdade de Medicina, Federal University of Minas Gerais,} Brazil

Correspondence: Nathalia Sernizon Guimarães, Faculdade de Medicina, Federal University of Minas Gerais, Rua SÃ $€ o$ Juliã $€ o$, Brazil,Tel 3 197772844,Email nasernizon@hotmail.com

Received: January 28, 2018 | Published: April 04, 2018

\section{Introduction}

According to the World Health Organization definition, palliative care refers to the assistance promoted by a multidisciplinary team that aims to improve the quality of life of patients and their relatives, in the face of a life threatening illness, through prevention and relief suffering, early identification, impeccable assessment and treatment of pain and other physical, social, psychological and spiritual symptoms. ${ }^{1,2}$

Several are the guiding principles of this multidisciplinary/multi professional health care. These include providing pain relief and other symptoms (eg, cachexia or dyspnea syndrome) and improving patient and family comfort. The work of a multi professional team is indispensable for this assistance to be carried out in an adequate manner, involving the participation of nutritionists, doctors, nurses, social workers, pharmacists, physiotherapists, occupational therapists, speech therapists and psychologists. The family also has an active and fundamental importance in this care. ${ }^{3-6}$ Nutritional care for palliativeness aims to promote well-being, control clinical signs and symptoms, and improve the quality of life of both patients and their families. Preserving body composition by delaying malnutrition, alternating feeding routes, reducing adverse effects caused by treatments and re-signifying food are key points in nutritional assistance. $^{7-9}$

As a justification study, the need for a scientific basis on the subject before the original studies, given the broad aspect given in review studies that focus on nutrition-oriented issues related to theory, in counterpart to the nutritionist's clinical practice. ${ }^{10,11}$ Given this context, this review aims to highlight, through the systematization of information search, the importance of nutritional care to the patient in palliative care under two different visions: the multidisciplinary team in health and patients/relatives.

\section{Methods}

This is a systematic review on the main functions and behaviors of the health professional Nutritionist before the patient in life termination. The search for information, presentation and interpretation of data was performed based on the PRISMA-P method. ${ }^{12}$

We included observational and interventional studies that evaluated the functions of the nutritionist and the impact of nutritional monitoring in this chronic stage. The exclusion criteria were divided into groups, described below: Group 1- articles in duplicate; Group 2studies published more than five years ago $(<2013)$; Group 3- studies with animals (experimental studies); Group 4- narrative, systematic reviews or meta-analyzes; Group 5- theme not attributed to the purpose of this review; Group 6- studies that did not mention the role of nutritionist; Group 7- studies performed in individuals who are not in palliative care. There was no restriction regarding the language, age, type of pathology or sex of the individuals investigated.

The original studies were identified through Medline, PubMed. The selection of terms (keywords or descriptor) for the search was performed by consulting the Medical Subject Headings (MeSH). After consultation, the descriptors were divided into two large groups (Nutrition and Palliative Care) and then paired using the Boolean search operators, ie quotes, parentheses, "AND" and "OR". The search strategy is presented in Table 1. All stages of study exclusion were independently performed by two authors of this review, in order to identify studies that potentially met the inclusion criteria described above. Any disagreement over the eligibility of the studies was resolved by the third reviewer.

\section{Results}

A total of 348 searches were identified. After applying the exclusion criteria by duplicate, by title, abstract and textual reading, respectively, two articles were selected to compose the present systematic review. 
Table 1 shows the flowchart of the article selection process. The included studies, detailed in Table 1, presented quasi-experimental design and cohort and were published in the years 2014 and 2017. In total, 161 individuals were argued about the issues related to Nutrition Science applied to palliative care.

Table I Nutrition and Palliative Care

\begin{tabular}{ll}
\hline Group & Descriptors \\
\hline \multirow{3}{*}{ Nutrition } & Food assistance \\
& Nutritional support \\
& Nutritional therapy \\
& Nutritional assessment \\
& Nutritionists \\
Palliative care & Palliative care \\
& Hospice care \\
\hline
\end{tabular}

The first evaluated study aimed to indicate, by nurses and physicians, the efficiency of nutrition care in palliative care within the multidisciplinary health team, based on three aspects: familiarity of professionals with theoretical concepts recommended for the subject addressed, knowledge of nutritional care and levels of knowledge among nurses and physicians on the subject. As a result, the researchers pointed out that the only significant difference between DNs and GPs at either baseline or follow-up was that on both occasions in the CG, DNs had greater perceived familiarity with information important to nutritional care in a palliative phase. Differences by profession in the IG and CG were found at baseline and/or follow-up in perceived familiarity (area 1) and perceived collaboration (area 2) but not in level of knowledge (area 3). ${ }^{13}$

The second study evaluated ${ }^{14}$ the improvement of the survival of a group of patients who had early nutritional follow-up, in detriment to patients who did not have this contact. The nutritional risk index was lower $(p<0.001)$ and the loss of attenuated body weight $(p<0.001)$ in the group with early intervention. Six deaths occurred during the study, five in the group that did not receive early nutritional intervention and one in the group that received the nutritional intervention $(p=0.06){ }^{14}$

\section{Discussion}

Palliative care applied to different areas of integrated health is a pertinent and current theme due to changes in the demographic and epidemiological profile of the population. ${ }^{15-17}$ Currently, the demographic pyramid tends to increase the aging population, the consequent increase in the frequency of chronic diseases and the difficulty of the health team to understand and offer comfort to the patients in the terminal state of life. ${ }^{16-18}$

Restricted publications were found and presented in our paper. The shortage in the number of research associating Nutrition with Palliative Care, when compared to studies involving questions about ethics, autonomy and death, ratifies the demand to broaden the debate and, moreover, for research and execution of $\mathrm{PC}$ in the routine of work of the nutritionist aiming to offer theoretical-scientific background. ${ }^{19,20}$ The inclusion of the theme will instill professionals in the reflection of the nutritional intervention focus of these patients, while offering comfort, relief and respect to the autonomy of the patient and their relatives, but acting with a clinical view on that critical situation, thus contributing to the improvement of the indicators of quality of life of these individuals. ${ }^{2,3}$

Although continuing education plays an important role in helping health care professionals achieve up-to-date knowledge, they often lack opportunities for continuing education adapted to the special context of their work. In addition, they lack educational contexts that support them in achieving the level of understanding required for applying knowledge in practice. It is also critical for health care professionals to cooperate with those close to the patient and to work in teams. ${ }^{21,22}$

We know of the limitations of a study with patients in palliative care, especially the possible reduced survival rate and number of losses increased. However, we must consider that, in the new concept of palliative care, any disease with poor prognosis should be included and the sooner the intervention, the more protected the patient will be. ${ }^{1,2}$ The inclusion of Nutrition in the team of health professionals who attend individuals in palliative care has a clinical and fundamental relevance. ${ }^{7-9}$ After knowing:

i. the prognosis of the disease.

ii. the life expectancy of the individual.

iii. the symptoms presented.

iv. the degree of reversibility of malnutrition, when applied, the discussion about which nutritional therapy is most appropriate should be a decision of the dietitian along with the patient, family member and team.

In this context, it is up to the Nutritionist to evaluate and inform the other members about the risks and benefits of the types of nutritional therapy (oral, enteral and parenteral) and, thus, promote a better quality of life for each individual. ${ }^{7,9,10}$ Adequate nutritional intervention promotes well-being, symptom control, and improved quality of life for patients and their families. The dietary approach must, above all, offer pleasure and comfort, respecting the autonomy of the patient and his family. Thus, along with other therapeutic measures, it may contribute to the promotion of the patients without clinical possibilities of cure. Hasenberg et al. ${ }^{23}$ found that early nutritional therapy can maintain body composition, improve life status and even prolong survival of patients who have suffered from cancer and are at palliative care. ${ }^{23}$

The nutritional behavior in palliative carfe should respect the decisions of the patient and his family, as well as bioethical principles: autonomy, beneficence, non-maleficence and justice. ${ }^{10,25}$ Because there is no scientific evidence for the decision to feed the patient or not, and because there is a significant cultural influence with regard to food, the decision to nourish to death the patient must be multiprofessional and have the consent of the family if the patient is unable to to decide..$^{25}$ If the patient chooses not to receive nutrition, his decision must be respected by health professionals and their families, since above all scientific evidence is the autonomy of the patient. This decision is not only technical, having a strong moral component involved, since food and hydration have a significant symbolic value in our society. ${ }^{25,26}$

According to Cañizo Fernández-Roldán ${ }^{25}$ giving food and drink is a significant action of respect for life and care for others. By food being directly associated with health and life, food deprivation means attempting against life. The idea of caring for food and its relation to life, once the individual in palliative care is still alive, must always be respected, since death can't and should not be anticipated. ${ }^{27}$

\section{Conclusion}

This work presented limitations regarding search sources. We conclude that, despite the obstacles, in general, nutritional care is 
important and widespread among other palliative professionals New research could be carried out with the purpose of directing the Nutritionist professionals in daily clinical practice.

\section{Acknowledgements}

None.

\section{Conflict of interest}

The author declares no conflict of interest.

\section{References}

1. http://www.who.int/cancer/palliative/definition/en/

2. http://www.secpal.com/guia-cuidados-paliativos-1

3. Academia Nacional de Cuidados Paliativos (ANCP). Manual de Cuidados Paliativos. Rio de Janeiro: Diagraphic; 2009. 338 p.

4. Reigada C, Ribeiro E, Novellas A. Indicators of ability to care, in families of cancer patients receiving palliative care. Palliat Med. 2010;4(1):165

5. Sapeta A. A família face ao doente terminal hospitalizado. Enfermagem Oncológica. 1998;2(8):20-24.

6. Remedios C, Thomas K. A systematic review of psychosocial interventions for family carers of palliative care patients. $B M C$ Palliat Care. 2010;9:17.

7. Corrêa PH, Shibuya E. Administração da terapia nutricional em cuidados paliativos. Rev Bras Cancerol. 2007;53(3):317-323.

8. Silva PB, Lopes M, Trindade LC, et al. Controle dos sintomas e intervenção nutricional. Fatores que interferem na qualidade de vida de pacientes oncológicos em cuidados paliativos. Rev Dor. 2010;11(4):282-288.

9. Shaw C, Eldridge L. Nutritional considerations for the palliative care patient. Int J Palliat Nurs. 2015;21(1):7-8.

10. Muir CI, Linklater GT. A qualitative analysis of the nutritional requirements of palliative care patients. J Hum Nutr Diet. 2011;24(5):470-478.

11. Morais SR, Bezerra NA, Carvalho NS, et al. Nutrição, qualidade de vida e cuidados paliativos: uma revisão integrativa. Rev dor. 2016;17(2):136-140.

12. Shamseer L, Moher D, Mike C, et al. Preferred reporting items for systematic review and meta-analysis protocols (PRISMA-P) 2015: elaboration and explanation. BMJ. 2015:349.
13. Berggren E, Olin AO, Orrevvall Y. et al. Early palliative home care: Evaluation of an interprofessional educational intervention for district nurses and general practitioners about nutritional care. SAGE Open Medicine. 2017;5:1-7.

14. Silvers MA, Savva J, Huggins CE, et al. Potential benefits of early nutritional intervention in adults with upper gastrointestinal cancer: a pilot randomised trial. Support Care Cancer. 2014;22(11):30353044.

15. Academia Nacional de Cuidados Paliativos. Critérios de qualidade para os cuidados paliativos no Brasil. Rio de Janeiro: Diagraphic, 2006.

16. https://www.cgee.org.br/

17. Instituto Brasileiro de Geografia e Estatística. Censo Demográfico 2010 - características da população e dos domicílios: resultados do universo Brasilia. Brazil: IBGE, 2010.

18. Rego S, Palácios M. A finitude humana e a saúde pública. Cadernos de Saúde Pública. 2006;22(8):1755-1760.

19. Pessini L, Bertachini L. Nuevas perspectivas en cuidados paliativos. Acta Bioethica. 2006;12(1):231-242.

20. The economist inteligence unit. The quality of death. Ranking endof-life care across the world. London: The Economist, 2010. 38 p.

21. Costa APP, Othero MB. Conceitos, princípios e formação em Cuidados Paliativos. Reabilitação em Cuidados Paliativos. Loures, Portugal: Lusodidacta. 2014;2(1):23-36.

22. Byock I. Principles of Palliative Medicine. In: Walsh D, editor Palliative Medicine. Philadelphia, USA: Saunders Elsevier: 2009. p. 33-41.

23. Hasenberg T, Essenbreis M, Herold A, et al. Early supplementation of parenteral nutrition is capable of improving quality of life, chemotherapy-related toxicity and body composition in patients with advanced colorectal carcinoma undergoing palliative treatment: results from a prospective, randomized clinical trial. Colorectal Dis. 2010;12(10):190-199.

24. Benarroz MDO, Faillace GBD, Barbosa LA. Bioética e nutrição em cuidados paliativos oncológicos em adultos. Cad Saúde Pública. 2009;25(9):1875-82.

25. Fernández-Roldán AC. Nutrición en el paciente terminal: punto de vista ético. Nutr Hop. 2005;20(2):88-92.

26. Pessini L, Bertachini L. Humanização e cuidados paliativos. Ciênc saúde coletiva. 2004;10(3):319.

27. Sochacki M, Barbosa, LA, Silva ACSB, et al. A dor de não mais alimentar. Rev Bras Nutr Clín. 2008;23(1):78-80. 